\title{
Seabed Observation and Sampling System
}

The SEABed Observation and Sampling System (SEABOSS) is designed by the U.S. Geological Survey (USGS) for rapid and effective collection of seabed images and sediment samples in coastal regions. The observations from video and still cameras and the sediment data are used to explore the nature of the seafloor and, in conjunction with sidescan-sonar and multibeam mapping surveys, to make interpretive maps of sedimentary environments and biological habitats.
The SEABOSS is a simple system that can be deployed from both small and large surface vessels. It incorporates two video cameras, a still camera, a depth sensor, and a modified Van Veen sediment sampler (fig. 1). The system's elements are held within a stainless steel framework that measures $1.2 æ 1.2 æ 1.2$ meters and weighs 136 kilograms overall. The frame has a stabilizer fin (fig. 2) that orients the system as it drifts over the seabed.

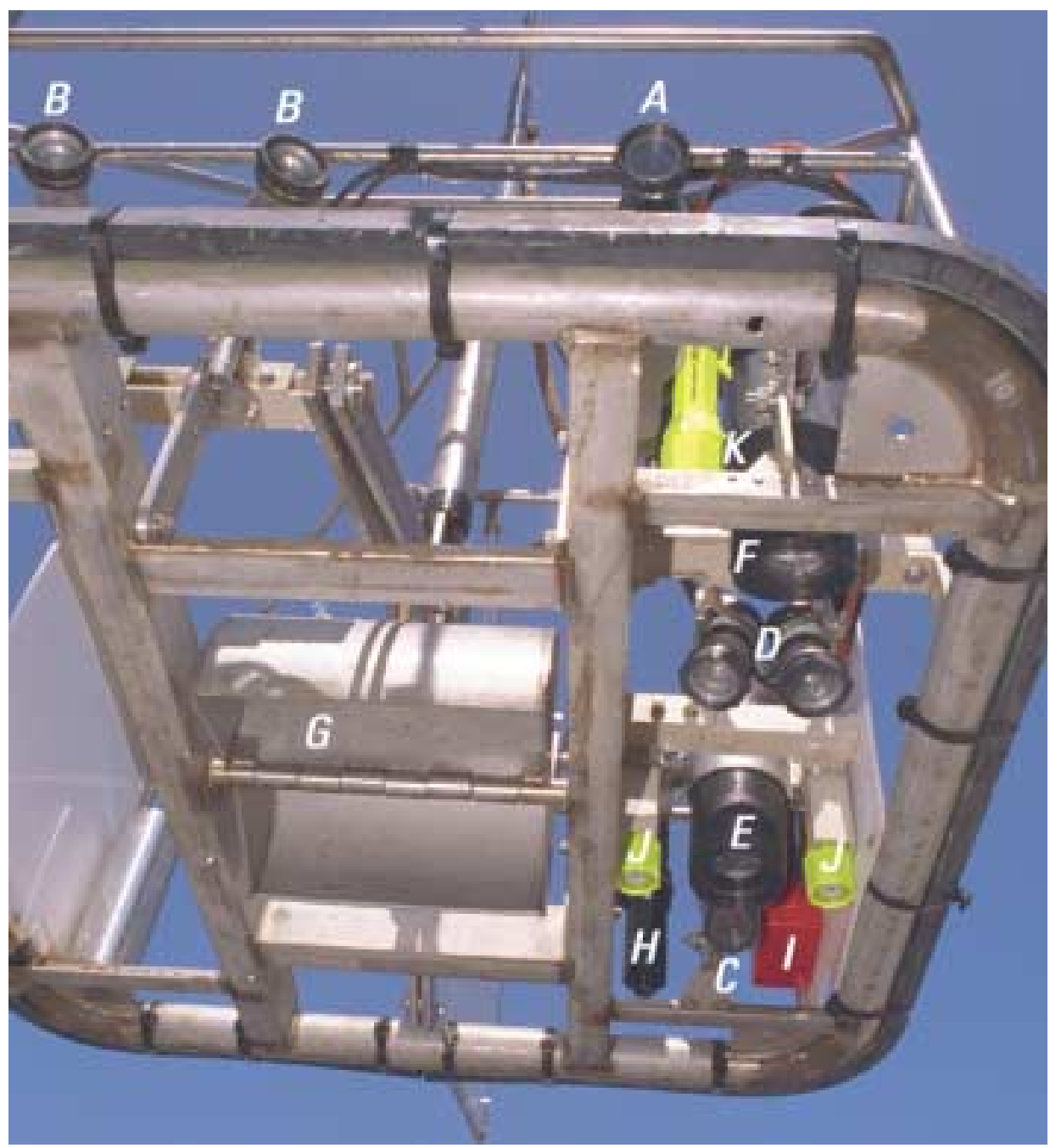

Figure 1. A view of the SEABOSS from below (with base plates removed; see fig. 2). Photograph by Dann B lackwood, USGS. The instruments are as labeled: A, forward-looking video camera; $B$, lights for forward-looking video camera; $C$, downward-looking video camera; $D$, lights for dow nward-looking video camera; E, 35-millimeter still camera; $F$, strobe light for still camera; $G$, modified Van Veen grab sampler; $H$, depth sensor; I, junction box; J , parallel lasers for scale; $K$, angled laser for range.

The modified Van Veen sediment grab in the center of the frame is triggered by resting the frame on the seabed for a few seconds; as the system is raised from the seabed, the grab bites into the sediment. The frame has adjustable, perforated base plates that can be lowered to prevent the grab sampler from sinking into soft bottoms and overfilling the bucket during sampling. The sampling bucket measures 30.48 centimeters square, is 15.24 centimeters deep, and samples an area of seabed measuring 0.1 meter square. It is very successful in collecting undisturbed samples. The bucket has a nonstick coating and is suitable for collecting samples to be analyzed for sediment chemistry.

One of the two video cameras is forward looking in order to capture an oblique view of the seabed and to warn of obstacles such as boulders that lie in the path of the system. The second video camera is downward looking, and its field of view overlaps that of a downwardlooking 35-millimeter still camera. The still camera usually is deployed 76 centimeters above the seabed, and it is capable of taking 250 photographs per roll. Parallel lasers (20 centimeters apart) are

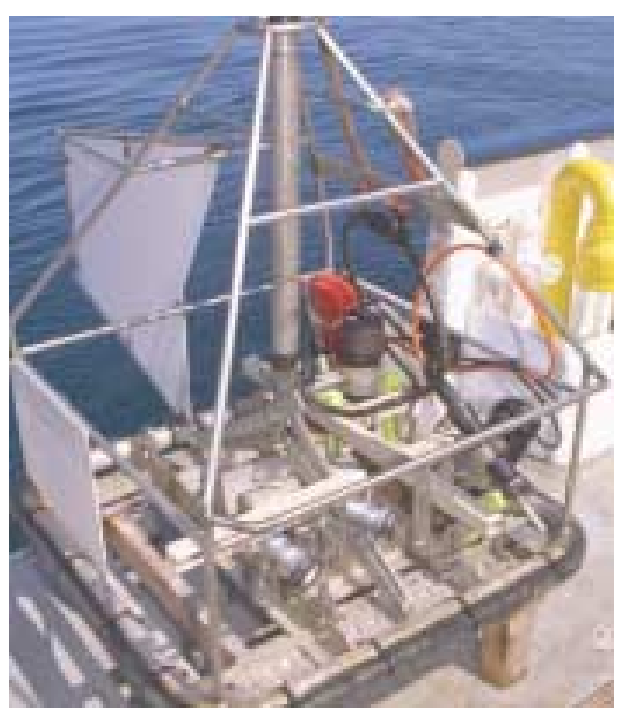

Figure 2. An oblique view of the SEABOSS on deck between stations. Photograph by Dann Blackwood, USGS. 
used to provide a scale for the video and photographic images; an angled laser is used to determine when the still camera is at an appropriate height for taking photographs of the seabed.

All of the systems are powered from the surface vessel through a conducting cable, except for the lasers, which are battery operated. The winch operator views a video monitor so that the system can be maintained at an appropriate height above the bottom and obstacles can be avoided. Scientists also view video monitors and decide when to sample and take still pho- tographs. Video displays include station number, water depth (from the depth sensor), and date, time, and geographic position (provided by a shipboard navigation system).

The SEABOSS allows scientists to collect high-quality images (fig. 3 ) and samples of the seabed. These images and samples are essential to the study of sedimentary environments and biological habitats and to the interpretation of sidescansonar imagery, the most common tool for mapping the seabed. The USGS has used the SEABOSS extensively in studies of the Stellwagen Bank National Marine Sanctuary, the New York Bight, Long Island Sound, Georges Bank, and areas off the coasts of Oregon and Washington.

\section{For more information, please contact:}

Page Valentine,

Dann Blackwood, or

Ken Parolski

U.S. Geological Survey

384 Woods Hole Road

Woods Hole, MA 02543

E-mail: pvalentine@usgs.gov

Telephone: (508) 457-2239

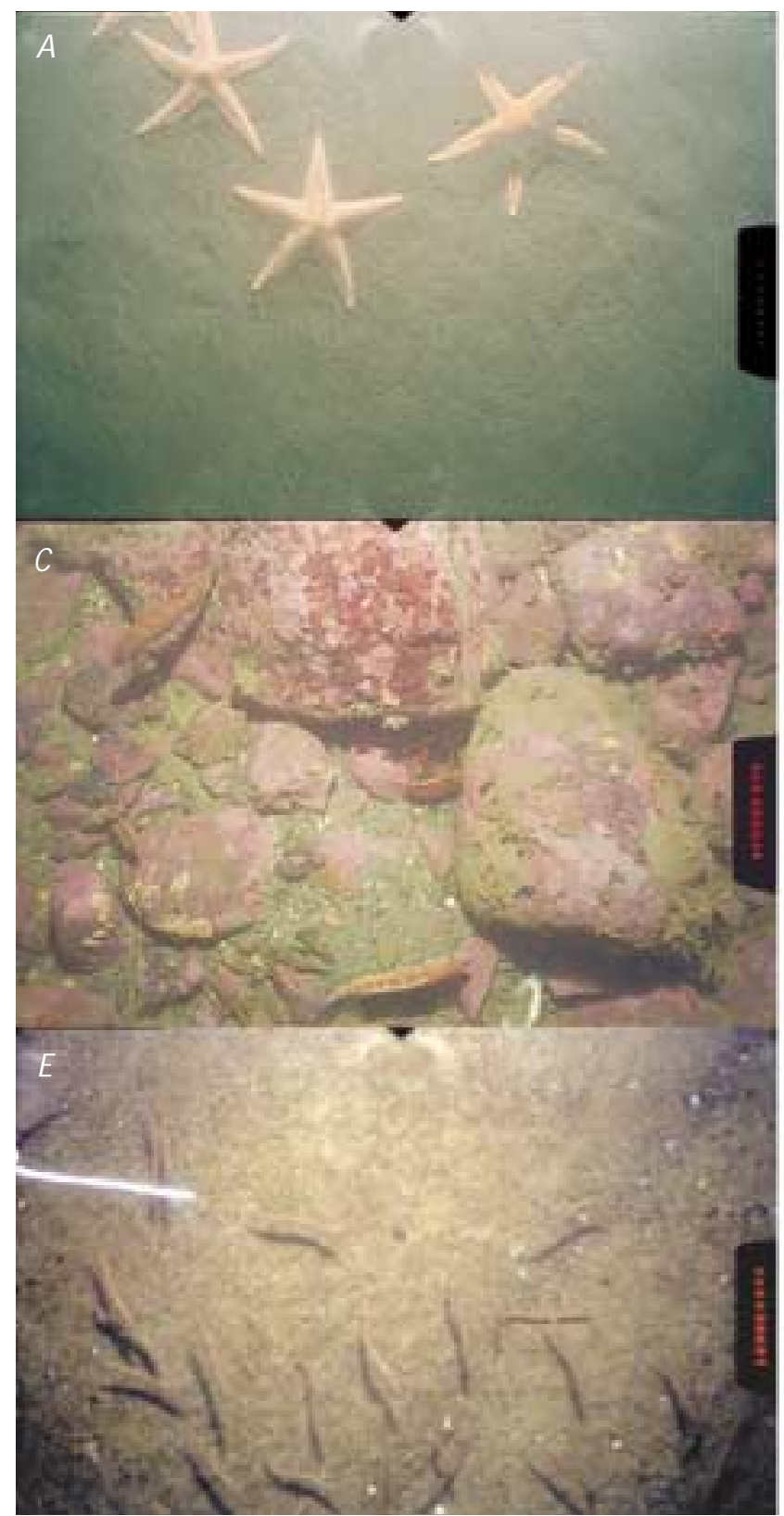

Figure 3. Examples of still photographs taken of different habitats $w$ ith the SEABOSS system during USGS studies. Area show $n$ in each photograph measures about $51 æ 76$ centimeters. A, Four starfish together on a muddy bottom in the New York Bight. B, J uvenile scallops swimming over a sandy bottom on Georges Bank. C, A boulder mound in western M assachu-

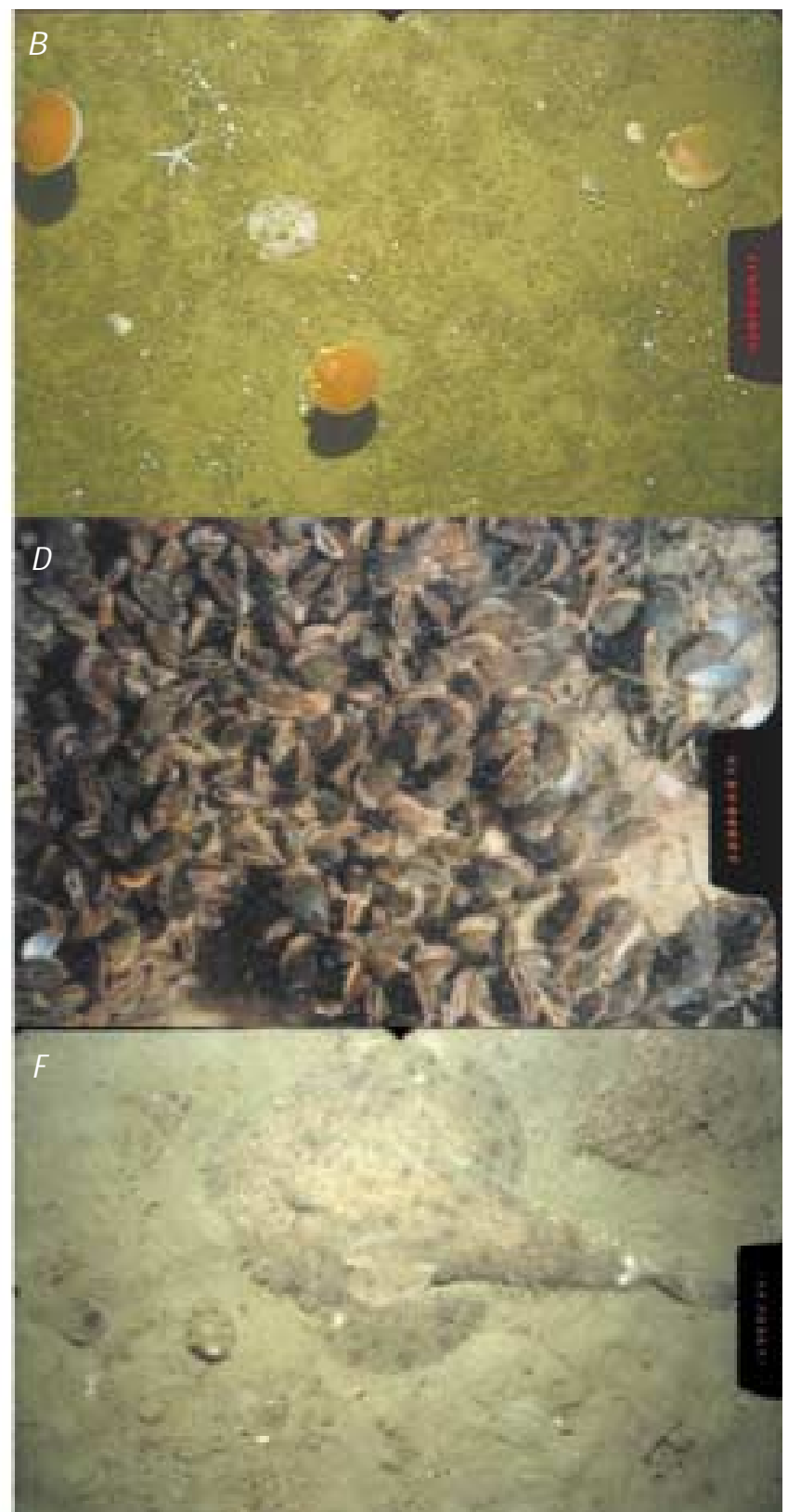

setts Bay that is providing habitat for lobster and fish. D, M ussels clustered on bedrock in Niantic Bay in Long Island Sound. $E$, Sand lance schooling over coarse sand in the Stellwagen Bank National M arine Sanctuary. F, A goosefish camouflaged on a muddy sand bottom in the Stellwagen Bank National Marine Sanctuary. 